\title{
Researchers ask for help to save key biopesticide
}

\section{- Crop pests already showing resistance to $B t$ - Report calls for industry, government curbs}

\section{Washington}

AGRICULTURAL researchers want the US government and industry to adopt a more careful use of the biopesticide bacillus thuringiensis $(\mathrm{Bt})$ to reduce the chances that crop pests will develop resistance to its toxicity.

In a report to be delivered later this month to officials from the US Department of Agriculture (USDA), government and academic researchers call for precautions and potential regulations that would prevent insects from becoming immune to $B t$. At stake is the viability of one of the most promising biopesticide ever developed.

Forty years ago $B t$ was just a bacteria found in ordinary dirt. Then, when researchers discovered that $B t$ produces toxic proteins that kill dozens of common insects (but are harmless to humans), it became a biopesticide to spray on crops. Over the last decade, however, as researchers discovered how to engineer the DNA of many plants so that they can express $B t$ toxins themselves, the simple bacteria has triggered a multi-million dollar research effort in agricultural industry to produce self-protecting crops that do not require chemicals to fight off pests.

Now, on the verge of a revolution in agriculture, researchers are afraid that $B t$ 's miracles could be coming to an end. Several US teams have managed to create $B t$ resistant pests in the laboratory in as little as 12 insect generations. And if it can be done in the laboratory, it can eventually happen in the real world, they argue, especially when $B t$-engineered plants reach widespread use.

Insects that are susceptible to $B t$ toxins are "a genetic resource" says Mark Whalon of the Michigan State University. "If we're not careful, we're going to lose them".

Last month, at a meeting sponsored by the USDA, government and academic researchers hammered out a strategy they hope can save $B t$. Their report is expected to contain 124 suggestions for research on $B t$ toxicity, monitoring programmes and precautions to avoid insect resistance.

Chief among the recommendations is an independant national advisory body that would serve as a $B t$ guardian. Reporting to the USDA, the group would recommend research on the biopesticide and monitor its use. Farmers will have to be careful not to rely on $B t$ alone, says Whalon, one of the authors of the report. Instead, he says, they should try to "keep the insects off balance" by mixing $B t$ with some traditional chemical pesticides, natural predators and other biotoxins.

Researchers also hope to encourage farmers to plant non- $B t$ plants alongside their engineered cousins that will serve as a haven (and genetic reservoir) for $B t$ susceptible pests. Varying the percentage of $B t$-expressing plants from zero to 50 per cent in a single field should also help to lower the percentage of pests with resistance by allowing susceptible insects (which usually have some other reproductive advantage over resistant insects) to

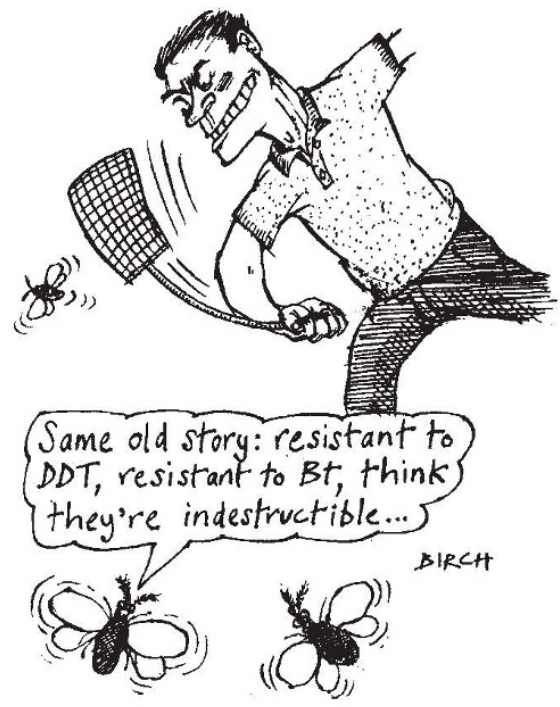

recover and drive out the competition.

Whalon has been able to breed Colorado potato beetles in the laboratory that show a 200 -fold increase in $B t$-resistance in 17 generations. He says that a comparable evolution would take just five years in nature. Whalon also bred his insects to be extremely susceptible to conventional chemical pesticides, so they could be quickly eradicated if they ever escaped. But naturally evolved resistant insects, in all likelihood, would not be so conveniently crippled.

Much of the $B t$ resistance that has appeared in the field is thought to be due to massive crop spraying of the $B t$ toxins themselves. The spraying has exposed insects to high doses and accelerated their rate of evolution into increasingly resistant breeds. Reports from at least four countries, including the United States, suggests that overuse of $B t$ by farmers has already produced some insects twice as resistant as those of just a few generations ago.
Officials at Monsanto Chemical Corporation, which is running one of the largest programmes to insert $B t$ resistance into crop plant DNA, say that its engineered plants are less likely to produce resistant pests. They explain that the toxins will come from inside the plants rather than from the outside, where they can wash away. That difference reduces the quantity of $B t$ that is released into the environment. In addition, the presence of $B t$ in the plant makes the insects vulnerable as soon as they begin to eat, at a point in their development when they are most susceptible.

Monsanto, too, is calling for a cropmanagement "regime" for $B t$-engineered plants. If such precautions are not adopted, company officials fear that their star performers will have lost their lustre by the time they reach the market in 1995.

Calling $B t$ susceptibility a "national resource", the researchers who met at the federal conference want the government to issue regulations on the use of the biopesticide. To date, however, federal agencies have not shown much interest. Unless the agencies have a change of heart, the best the $B t$ sentries can hope for are federal guidelines and help from companies such as Monsanto in encouraging farmers to use the engineered plants with care. But if the experience with sprayed $B t$ is an guide, that will be an uphill battle.

Christopher Anderson

JAPANESE SATELLITE

\section{Earth monitor fails}

Tokyo

JAPAN's first earth resources satellite, Fuyo1, which was launched last week by the National Space Development Agency (NASDA), has run into serious trouble and may not be able to fulfil its main mission to search for mineral and oil resources around the world with a new high-technology radar system.

Shortly after launch, the 12-metre antenna of the Synthetic Aperture Radar (SAR) - the satellite's key sensor - failed to open fully on command from the ground. The reason for the jamming remains unknown.

The other optical sensors on the satellite are functioning normally, but they cannot see through cloud cover. The SAR is an active sensor that bounces microwaves off the Earth's surface and can determine surface characteristics, such as undulations, with a resolution of 18 metres regardless of cloud cover.

Fuyo-1 is the largest satellite ever launched by Japan. NASDA engineers have not yet given up hope; they say there are cases where a satellite's jammed antenna has opened, without permanent damage, as long as three months after launch.

David Swinbanks 